\title{
PENDIDIKAN POLITIK ISLAM MELALUI ORGANISASI KEMAHASISWAAN
}

\author{
Hasbullah $^{1}$, Najib Husain ${ }^{2}$, Asriani $^{3}$ \\ Universitas Halu Oleo, hasbullah.politik@gmail.com \\ Universitas Halu Oleo, najib_75husain@yahoo.co.id \\ Universitas Halu Oleo, asrianifisip77@uho.ac.id \\ Kota Kendari
}

\begin{abstract}
ABSTRAK
Penelitian ini bertujuan untuk mengetahui proses pengkaderan yang dilakukan Lembaga Dakwah Kampus Unit Kegiatan Kerohanian Islam Untuk mengetahui pendidikan politik Islam yangdilakukan melalui pengkaderan Lembaga Dakwah Kampus Unit Kegiatan Kerihanian Islam.Penelitian ini dilaksanakan pada bulan Mei 2018 hingga Agustus Oktober 2019.Penelitian ini menggunakan konsep pendidikan politik Surbakti dan metode penelitian yang digunakan dalam penelitian ini yaitu metode kualitatif data yang di peroleh melalui observasi dan wawancara selain itu pula di dukung dengan dokumentasi studi pustaka. Tehnik penentuan informan dalam penelitian ini adalah menggunakan purposive sampling, informan dalam penelitian ini terdiri dari informan kunci dan informan biasa sebanyak 10 orang.Hasil penelitian menunjukan bahwa proses pengkaderan yang terjadi di Lembaga Dakwah Kampus Unit Kegiatan Kerihanian Islam Universitas Halu Oleo sangat sistematis. Dalam kegiatan pengkaderan yang dilaksanakan mempunyai tahapan-tahapan sesuai dengan pedoman pengkaderan Lembaga Dakwah Kampus Unit Kegiatan Kerihanian Islam Universitas Halu Oleo. Dan pendidikan yang diberikan kepada mahasisawa dalam pengkaderan di Lembaga Dakwah Kampus Unit Kegiatan Kerihanian Islam Universitas Halu Oleo melalui kegiatan: Kursus, Altadrib eala Alqiada, Munaqhasa serta Al Musharakat Fi Mutadaa Alaijmae hal ini dapat mempengaruhi dan meningkatkkan pengetahuan politik Islam pada mahasiswaDiharapkan Lembaga Dakwah Kampus Unit Kegiatan Kerihanian Islam Universitas Halu Oleo lebih memaksimalkan dan lebih mengefektifkan perannya dalam kegiatan pengkaderan agar terlaksanya tujuan pendidikan politik islam di kalangan mahasiswa.
\end{abstract}

Kata Kunci: Pendidikan Politik Islam, Pengkaderan, Organisasi kemahasiswaan, LDK UKKI 


\begin{abstract}
This study aims to determine To megadad the cadre process carried out by the Islamic Propagation Institute of Islamic Spiritual Activity Unit To find out the Islamic political education carried out through the cadre of Islamic Campus Propagation Activities Unit of Islamic Devotion Activities Unit .This research was conducted in May 2018 until August October 2019. This research uses the concept of Surbakti political education and the research method used in this study is the qualitative method of data obtained through observation and interviews while also supported by documentation of library studies. The technique of determining informants in this study was using purposive sampling, the informants in this study consisted of 10 key informants and regular informants. The results showed that the cadre process that took place in the Institute of Islamic Spiritual Activity Unit University Halu Oleo was very systematic. The cadre activities carried out have stages in accordance with the guidelines of the Institute of Islamic Spiritual Activity Unit University Halu Oleo cadre. And education provided to students in cadreing at Institute of Islamic Spiritual Activity Unit University Halu Oleo through activities: Kursus, Altadrib eala Alqiada, Munaqhasa and Al Musharakat Fi Mutadaa Alaijmae, this can influence and increase Islamic political knowledge in students. It is hoped that the Institute of Islamic Spiritual Activity Unit University Halu Oleo will further maximize and more effective its role in cadre activities in order to carry out the objectives of Islamic political education among students.
\end{abstract}

Keywords: Islamic Political Education, Cadre, Student Organizations, LDK UKKI 


\section{PENDAHULUAN}

Pendidikan merupakan bagian dari kebutuhan mendasar manusia (al-hajat al-asasiyyah) yang harus dipenuhi oleh setiap manusia seperti halnya pangan, sandang, perumahan, kesehatan, dan perumahan pendidikan adalah bagian dari masaalah politik (siyasah) yang diartikan sebagai ri'ayah asy-su'un al-ummah (pengelolaan urusan rakyat) berdasarkan ideologi yang diemban negara tersebut.

Indonesia adalah negara yang memiliki populasi islam terbesar di dunia. Pada saat ini di perkirakan bahwa jumlah umat Islam mencapai 207 juta orang. Jumlah yang besar ini mengimplementasikan bahwa sekitar 13\% dari umat muslim di seluruh dunia tinggal di indonesia dan mengimplikasikan bahwa mayoritas populasi penduduk di indonesia memeluk agama Islam, kendati mayoritas penduduk beragama Islam, negara ini bukanlah negara Islam yang berdasarkan pada hukum-hukum Islam. Padahal seharusnya ketika dalam satu negara mayoritas umat Islam maka segala keputusan akan berlandaskan pada sistem Islam termasuk dalam perkara politik harus belandaskan pada ideologi Islam.

Politik Islam memberikan pengurusan atau urusan seluruh umat Islam. Namun realitasnya politik berubah menjadi pudar saat terjadi kebiasaan umum masyarakat, baik itu perkataan maupun perbuatanya yang menyimpang dari kebenaran. Islam yang dilakukan oleh mereka yang tidak beraqidah tidak baik, baik itu dari kalangan non muslim ataupun dari kalangan muslim itu sendiri. Oleh karena itu politik yang seharusnya bersifat baik menjadi kurang baik seperti kedustaan, tipu daya, dan penyesatan yang di lakukan oleh para politisi penguasa.

Penyalahgunaan wewenang dari pada politisi atau penguasa itu bersebrangan dengan kebenaran Islam, kezaliman mereka kepada masyarakat, sikap dan tindakan semborono dalam mengurusi masyarakat memalingkan makna dari politik Islam itu sendiri, bukan sebagai perintah yang shalih dan berbuat baik kepada masyarakat. Hal ini dapat memicu bahwa politik itu harus di jauhkan dari agama Islam, sebab orang yang paham agama itu takut kepada Allah SWT sehingga tidakcocok kerkecipung dalam politik yang merupakan dusta,kezhaiman, penghianatan dan tipu daya. Padahal definisi politik Islam itu adalah sikap, perilaku dan kebijakan kemasyarakatan yang mendekatkan pada kemaslahatan, sekaligus menjauhkan dari kemafsadahan, meskipun belum pernah ditentukan oleh Rasulullah SAW. 
Pendidikan politik Islam harus kita pahami sebagai upaya mengubah manusia dengan pengetahuan tentang sikap dan perilaku yang sesuai dengan kerangka nilai/ideologi Islam. Dengan demikian, pendidikan politik Islam merupakan proses mendekatkan manusia pada tingkat kesempurnaannya dan mengembangkan kemampuannya yang dipandu oleh ideologi/akidah Islam.

Pendidikan politik Islam adalah hak mutlak yang harus di terapkan di semua eleman masyarakat terutama kepada kaum inteluktual dalam hal ini adalah mahasiswa, karena sangat penting bagi kehidupan berbangsa dan bernegara.

Oleh sebab itu maka sangat penting pendidikan politik Islam di berikan kepada mahasiswa dan pendidikan politik Islam juga bisa didapat di berbagai elemen masyarakat diantaranya adalah partai poitik Islam, lembaga swadaya masyarakat dan organisasi kemahasiswaan.

Seperti yang di kemukakan Ramlan surbakti, 1999:117 yang mengartikan bahwa pendidikan politik sebagai suatu dialogi antara pemberi dan penerima pesan. Adapun bentuk dari pendidikan politik Islam adalah dilakukan memulai Kursus, Training Kepemimpinan, Diskusi dan Keikut sertaan dalam forum pertemuan.

Organisasi kemahasiswaan adalah komponen penting dalam proses pendidikan mahasiswa UHO sebagai manusia dewasa calon khalifah (pemimpin) bangsa. Peran aktif mahasiswa dalam organisasi kemahasiswaan merupakan proses pengembangan karakter unggul khususnya aspek softskills baik aspek intrapersonal maupun interpersonal mahasiswa. Organisasi kemahasiswaan juga memegang peranan penting sebagai salah satu aktor utama dalam pencapaian tujuan yaitu membangun keunggulan mahasiswa UHO sebagai insan UlilAlbaab yang mampu menjadi pengejawantahan nilai-nilai Rahmatan lil 'alamin.

Organisasi kemahasiswaan di UHO tersebar di tingkat Universitas, Fakultas, sampai Program Studi. Bentuk organisasi kemahasiswaan dapat berupa Lembaga Mahasiswa, Lembaga Khusus, Unit Kegiatan Mahasiswa (UKM), Unit Bidang Penalaran, Lembaga Dakwah Kampus, Berbagai organisasi kemahasiswaan tersebut berada di bawah naungan Bidang Kemahasiswaan Universitas atau Bidang Kemahasiswaan Fakultas. 
Lembaga dakwah kampus adalah sebuah organisasi lingkup kampus ayng memiliki SDM yang telah terstruktur. Lembaga dakwah kampus dalam hal ini adalah Unit Kegiatan Kerohanian Islam Universitas Halu Oleo (UHO) merupakan organisasi dakwah yang memiliki sistem politik Islam dalam menjalankan tugas-tugasnya sebagai organisasi kemahasiswaan.

Lembaga Dakwah Kampus Unit Kegiatan Kerohanian Islam Universitas Halu Oleo atau disingkat (LDK UKKI UHO) adalah sebuah unit kegiatan Mahasiswa(UKM) resmi di universitas halu oleo yang tidak jauh beda dengan organisai-organisasi lainya tapi dari segi pembentukan karakter Islami sangat berbeda dengan lembaga lain. Yang membedakan LDK UKKI dengan yang lain diuniversitas halu oleo adalah dimana di Universitas Halu Oleo terdapat tiga lembaga dakwah kampus yaitu LDK Ulul Albab, LDK Badan koordinator lembaga dakawah mahasiswa (BKLDM) dan LDK UKKlitu sendiri. Dimana LDK UKKI tidak hanya focus pada dakwah tetapi selalu turut andil dalam menganggapi perpolotikan kampus dan sebagai faktaya adalah setiap pemilu raya yang diadakan oleh Uiversitas LDK UKKI seklalu mengutus kadernya untuk ikut dalm perta demokrasi tersebut. Inilah yang membedakan dengan organisasi lainya karena organisasi UKM UKKI UHO pada umumnya terkenal dengan diri kepribadian intelektual, berwatak krisis, berkarakter Islami, berkahlak mulia, memiliki hubungan emosional sehingga tidak bisa di pungkiri bahwa pembentukan pendidikan Islam berawal dari aksi lembaga dakwah kampus UKKI UHO yang peduli terhadap perbaikan kampus. Dari tahun ke tahun sistem pergantian kekuasaan lembaga kemahasiswaan di kampus UHO selalu mengalami keributan, menunjukan akhlak yang tidak baik bahkan sampai pada tahap saling membenci satu sama lain.

Kejadian-kejadian seperti itu selalu kita jumpai dan kita lihat dalam pesta demokrasi kemahasiswaan di Kampus Univeristas Halu Oleo, dan tidak banyak di antara kita memundurkan diri sebagai calon ketua atau wakil ketua pada pesta demokrasi kampus tersebut karena melihat kondisi atau kejadian yang tidak menonjolkan sistem politik yang baik. LDK UKKI UHO selalu terlibat diri dalam pesta demokrasi UHO, tidak peduli dengan kondisi lingkungan yang selalu mengancam, karena LDK UKKI UHO Punya misi yaitu menjadikan kampus yang lebih Islami, sehingga dalam sistem politik kampuspun harus Islami. 
Proses pendidikan politik Islam yang di lakukan oleh LDK UKKI UHO melewati proses panjang mulai pada persiapan hingga pada proses melaksanakan. Tahap pelaksanaan pendidikan Islam LDK UKKI UHO berbeda dengan beberapa lembaga dakwah kampus lainya, kerena organsasi LDK UKKI UHO ini di bentuk dengan tujuan khusus yaitu menyiarkan nilai-nilai Islam ditataran civitas akademika kampus. LDK UKKI UHO memiliki pandangan bahwa sistem politik Islam yang di pahami adalah mengubah manusia dengan pengetahuan tentang sikap dan perilaku yang sesuai dengan kerangka nilai atau ideologi Islam, Dakwah Islam yang telah berlangsung pada LDK UKKI ini pada intinya adalah sebuah proses dan upaya tabligh dalam arti menyampaikan kebenaran ajaran agama untuk membangun tatanan kehidupan yang penuh kedamaian dan jauh dari dendam masa lalu serta berusaha menatap ke depan yang lebih baik.

Politik Islam membawa manusia dari jahiliyah menuju Islamiah, dari keadaan terpuruk menjadi penuh kemaslahatan, dan keadaan yang tidak mengindahkan aturan menuju keadaan yang memahami serta menaati peraturan dan begitu seterusnya karena LDK UKKI UHO ada banyak agenda yang merupakan bagian dari sistem pendidikan politik Islam. Kebenaran kegiatan yang diyakini LDK UKKI UHO bahwa berpolitik bagian dari dakwah dan dakwah merupakan tujuan dari berpolitik. Karena Islam yang di pelajari tidak hanya hadir di wilayah kematian, formalitas pertemuan dan wilayah kaku lainnya.

Berdasarkan hasil survei yang di lakukan oleh LDK UKKI UHO pada tahun 2018 bahwa LDK UKKI UHO mampu mengantarkan beberapa anggotanya menjadi anggota MPM UHO, ketua BEM fakultas, anggota BEM Fakultas, ketua DPM fakultas, anggota DPM Fakultas, ketua HMJ, Ketua UKM lainya, itu adalah salah satu bukti bahwa LDK UKKI UHO berhasil berkontribusi dalam pendidikan politik di kalangan mahasiswa, padahal lembaga LDK UKKI UHO tidak memiliki afiliasi payung partai politik yang ada di Indonesia. Pada tahun 2017 anggota LDK UKKI UHO bisa duduk di kursi legislatif, yudikatif kampus UHO kurang lebih 43\%. Tahun 2018 anggota LDK UKKI yang lulus dalam pesta demokrasi kampus meningkat menjadi 49\%.(Sekretariat LDK UKKI UHO 2019).

Hal inilah yang membuat peneliti tertarik utnuk mengadakan penelitian pada organisasi kemahasiswaan lembaga dakwah kampus UKKI UHO tentang bagaimana pendidikan politik 
Islam. sebuah organisasi lembaga dakwah kampus yang tidak memiliki afiliasi partai politik tapi mampu terlibat aktif dalam pesta-pesta demokrasi kampus. Mungkinkan ini di sebabkan oleh kegiatan-kegiatan yang di lakukan oleh LDK UKKI UHO bernuansa Islami. Atas dasar itulah membuat peneliti merasa tertarik untuk meneliti "Pendidikan Politik Islam Melalui Organisasi Kemahasiswaan Studi Pada Pengkaderan Lembaga Dakwah Kampus Unit Kegiatan Kerohanian Islam (LDK UKKI) Universitas Halu Oleo.

Rumusan masaalah, Berdasarkan latar belakang tersebut diatas, maka rumusan masaalah dalam penelitian ini adalah Bagaimana pendidikan politik Islam yang dilakukan melalui pengkaderan Lembaga Dakwah Kampus Unit Kegiatan Kerihanian Islam (LDK UKKI).? Tujuan Penelitian Adapun tujuan dari peneleitian ini adalah sebagaai berikut: untuk mengetahui pendidikan politik Islam yangdilakukan melalui pengkaderan Lembaga Dakwah Kampus Unit Kegiatan Kerihanian Islam (LDK UKKI).

Manfaat Penelitia Penelitian ini dapat bermanfaat dalam pelaksanaan perkuliahan pada program studi ilmu politik, oleh karna itu hasil pelitian ini di harapkan memiliki kegunaan yaitu : (1) Manfaat Secara Teoritis, Manfaat secara teoritis adalah untuk menambah, memperdalam, memperjelas memperkuat teori serta pengembangan ilmu yang berkaitan, khususnya di bidang penelitian pendidikan ilmu politik. pengembangkan ilmu politik, khususnya pendidikan politik Islam bagi mahasiswa serta sabagai salah satu sumber referensi guna melakukan penelitian lebih lanjut tentang organisasi kemahasiswaan sebagi sarana pendidikan politik bagi mahasiswa.(2) Manfaat secara praktis, Manfaat secara praktis adalah diharapkan menjadi salah satu sumber referensi bagi para pencinta ilmu pengetahuan khususnya di program ilmu politik serta dapat memberikan perkembangan pemikiran yang lebih maju lagi dan baik bagi semua kalangan serta dapat mengetahui pendidikan politk Islam mahasiswa melalui organisasi kemahasiswaan didalam pengkaderan lembaga dakwah unit kegiatan kerohanian Islam.(3) Manfaat Metodologi,

Penelitian ini tentang pendidikan politik Islam melalui organisasi kemahasiswaan yang bertujuan untuk memaparkan bagaimana proses pendidikan politikIslam yang dilakukan oleh LDK UKKI UHO dengan menggunakan konsep pendidikan politik (surbakti, 1999:117) yang mengartikan bahwa pendidikan politik sebagai suatu dialogi antara pemberi dan penerima 
pesan. Adapun bentuk dari pendidikan politik Islam adalah dilakukan memulai Kursus, Training Kepemimpinan, Diskusi dan Keikut sertaan dalam forum pertemuan.

\section{METODE PENELITIAN}

Dalam penelitian ini menggunakan metode kualitatif deskriptif, penelitian kualitatif adalah prosedur penelitian yang menghasilkan data deskriptif berupa kata-kata tertulis, gambar, yang mana data diperoleh dari orang-orang dan perilaku yang dapat diamat (Maloeng, 2000).Oleh karena itu, penelitian ini menggunakan metode kualitatif deskriptif karena data-data yangdigunakan berupa kata-kata, gambar. Penelitian kualitatif merupakan proses penelitian yang berkesinambungan sehingga tahap pengumpulan data, pengolahan data, dan analisis data dilakukan secara bersama selama proses penelitian.

Penelitian ini dilakukan di Universitas Halu Oleo Kendari, tepatnya pada sekretariat Lembaga Dakwah Kampus Unit kegiatan UK-Kerohanian Islam. Alasan pemilihan lokasi karena data penelitian yang akan di ambil adalah pada organisasi tersebut.

Subyek dalam penelitian ini adalah seluruh mahasiswa yang telah mengikuti pengkaderan di dalam organisasi kemahasiswaan LDK UKM UK-kerohanian Islam Universitas Halu Oleo.Informan penelitian merupakan orang yang faham dan mengerti tentang sesuatu yang di perlukan oleh peneliti dalam penelitiannya.Seperti yang dikemukakan oleh Bungin. Informan penelitian adalah yang memahami informasi objek penelitian sebagai pelaku maupun orang lain yang memahami objek penelitian (Burhan Bungin, 2011:78).Teknik penentuan informan dalampenelitian ini dilakukan secara purposive sampling dimana informan dipilih secara sengaja dengan pertimbangan tertentu (Sugiyono, 2006).

Pemilihan informan tersebut berdasarkan pada pertimbangan sebagai berikut: (1) Informan yang dipilih mampu menjawab rumusan masaalah penelitia dalam artian menguasai atau memahami masaalah yang diteliti.(2) Informan mempunyai cukup waktu untuk diwawancarai

Adapun jenis data yang akan digunakan dalam penelitian ini adalah data kualitatif, dimana data kualitatif yang akan disajikan dalam bentuk narasi untuk mendeskriptifkan hal-hal mengenai pendidikan politik mahasiswa dalam proses pengkaderan LDK UKM UK- 
kerohanian Islam Universitas Halu Oleo. Hal ini akan dipaparkan berdasarkan alamiah dilokasi penelitian (Natural Setting).

Dalam penelitian ini diperoleh dari dua sumber yaitu: (1)Data Primer adalah data yang diperoleh langsung dari sumber asli atau informan kunci. Penelitian ini melalui tahap wawancara mengenai pendidiakan politik mahasiswa terhadap proses pengkaderan LDK UKM UK-Kerohanian Islam Universitas Halu Oleo.(2)Data sekunder yaitu data yang berupa catatan-catatan dari dokumen yang terdapat di LDK UKM UK-Kerohanian Islam Universitas Halu Oleo. Data sekunter berupa arsip atau dokumentasi pada saat pengkaderan LDK UKM UK-Kerohanian Islam Universitas Halu Oleo dan data yang relevan dengan permasaalahan penelitian.

Tehnik Pengumpulan Data melalui (1)Pengamatan(Observasi) yaitu peneliti akan meninjau dan mengamati langsung bagaimana pendidikan politik yang diberikan dalam setiap aktifitas kegiatan LDK UKM UK-Kerohanian Islam Universitas Halu Oleo. Dan (2)wawancara(interview) yaitu peneliti akan mengumpulkan data di lapangan melalui wawancara langsung kepada informan untuk mendapatkan data terkait permasaalahan yang diteliti, wawancara akan terus dilalukan selama berlangsungnya penelitian hingga mencapai data penuh. Serta (3) dokumentasi yaitu peneliti akan mengumpulkan data dengan menggunakan foto-foto dan data sekunder dengan mengambil data dari secretariat LDK UKM UK-Kerohanian Islam Universita Halu Oleo

Teknik analisis data yang digunakan dalam penelitian ini sebagaaimana yang digambarkan oleh Miles dan Huberman (1992) yang serti yang tampak pada penjelasan dibawah ini: (a)Pengumpulan data, yaitu mengumpulkan data di lokasi studi dengan melakukan observasi, wawancara mendalam dan mencatat dokumen dengan menentukan strategi pengumpulan data yang dipandang cepat sertauntuk menentukan focus maupun pendalaman data pada proses proses pengumpulan data berikutnya.(b)Reduksi data yaitu sebagai proses seleksi, pemfokusan, pengabstrakan, transformassi data kasar yang ada dilapangan langsung dan di tentukan pada waktu pengumpulan data, dengan demikian reduksi data dimulai sejak difokuskannya wilayah penelitian.(c)Sajian data, yaitu rakitan organisasi reformsi yang memungkinkan penelitian dilakukan. Penyajian data meliputi berbagai jenis matrik, gambar, 
jaringan kerja keterkaitan dan kegiatan atau tabel.(d)Penarikan kesimpulan, yaitu dalam pengumpulan adta peneliti harus mengerti dan tanggap terhadap sesuatu yang diteliti langsung di lapangan dengan menyusun pola-pola pengarahan dan sebab akibat.

\section{HASIL DAN PEMBAHASAN}

pelaksanaan pengkaderaan yang terjadi di LDK UKKIUHO sangat sistematis, Terbagi menjadi dua bagian yaitu formal dan non formal, untuk pengkadran secara formal ada yang namanya Tadrib, di UKKI itu sendiri Tadrib ada dua tingkatan, yaitu Taining tingkat satu dalam organisasi kami disebut Tadrib mustawaan wahid atau di sebut juga TR-1 dan Training Tingkat dua (Tadrib mustawaan alththani) atau TR-II. dalam pelaksanaan TR-I dan TR-II itu biasnya setia tahun atau setiap periode kepengurusan materi-materi yang diberikandalam TR-I ini meningkatkan pemahaman kader akan dasardasar berorganisasi serta membangunn kemampuan kekhalifahn mahasiswa dan juga mempercepat dan meningkatkan kemampuan menejemen mahasiswa serta mengasah kemampuan kader demi persiapan calon-calon pengurus LDK selanjutnya, sebenarnya materi-materi yang diberikan TR-I ini tdak terlepas dari tujuan LDK UKKI tu sendiri. kalau soal pendidikan politik Islam kader itu akan memahami dengan sendirinya jika terusmenerus mengikuti kegiatan-kegiatan UKKI itu sendiri, sebab LDK UKKI itu memahamkan kepda kader-kadernya tentang bagaimana kita menerapkan aturah-aturan Islam dalam diri kita, keluarga kita, lingkungan bahkkan sampai pada politik harus tetap pada aturan Islam.

pendidikan politik Islam yang dilakukan oleh ukki daalam pengkaderan itu sebenarnya cukup bagus sejauh ini, karna saya sendiri merasakan itu selama saya dikader di lembaga ini asalkan kita mengikuti semua rangkayan kegiatan yang di lakukan oleh ukki, coba kita lihat ukki itu punya kajian khusus membahas strategi kemenangan Islam dimassa rasulllah dan parasahabat bukannya itu termasuk strategi politik. dengan seringnya kader mengikuti kajian seperti ini makan politik Islam akan terbentuk dgnan sedirinya.

LDK UKKI telah menisbatkan dirinya sebagai lembaga dakwah yang mempunya ciri khas tersendiri. Memperjuangkan tegaknya nilai-nilai Islam di muka bumi khususnya di lingkup Universitas Halu Oleo. Hal ini oleh kekuatan mutiara illahi yang tertuang dalam surah AshShaf: 4 


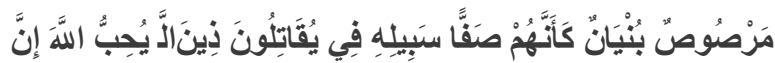

Artinya: "Sesungguhnya Allah SWT menyukai orang yang berjuang dijalan-Nya dalam barisan yang teratur seakan-akan mereka seperti suatu bangunan yang tersusunkokoh". Agama Islam melalui esensi reformasinya telah mewrnai berbagai dimensi kehidpan dan menjelaskan secara komprehensip problematika manusia.

Ada sebuah fenomena kehidupan berdemokrasi kampus dibalik predikat dan peranannya yang vital, ternyata nampak kian hari kian tidak terkontrol yakni kampus juga menimbulkan sumber-sumber kemaksiatan yang terselubung yang tidak terelakan mulai dari budaya kekerasan, premanisme, kumpul kebo, tawuran antar lorong, pengedar dan pemakai obat terlaran,Sebuah ketetapan sunatullah bahkan minyak dan air tidak akan pernah menyatu, hitam dan putih akan menjadi warna berbeda, begitu juga antara kebaikan dan kemungkaran akan selalu bertarung dalam realita kehidupan kita. Untuk itu mahasiswa memiliki kapasitas menjadi khalifah masa depan umat, seharunya dibekali dengan pola pikir sehat, aqidah yang benar dan akhlakul kharimah yang baik. Oleh karna itu, sebagai insan akademis muslim, kita mempunyai hak, tanggung jawab untuk memperjuangkan, menegakkan, mengamalkan, dan mendakwahkan Islam disegala aspek kehidupan hingga kehidupan berpolitik sehingga mencapai masyarakat yang Islami.Sebagai wujud tanggung jawab tersebut, maka Lembaga Dakwah Kampus UKKI mmembentuk sebuah wadah guna menyatukan sebuah visi dan misi para aktivisnya sebagai langkah mencapai tujuan pembentukan moralitas Islami genersi muda masa depan bangsa khususnya mahasiswa Universitas Halu Oleo

\section{Pendidikan Politik Islam Yang Diberikan Kepada Mahasiswa Melalui Pengkaderan Lembaga Dakwah Kampus UKKI Universitas Halu Oleo}

\section{Kursus}

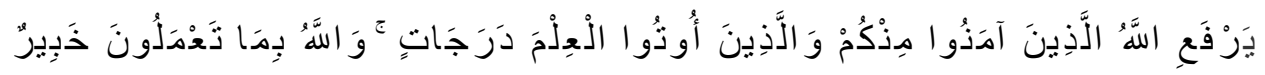

"Allah akan meninggikan orang-orang yang beriman di antaramu dan orang-orang yang diberi ilmu pengetahuan beberapa derajat (Q.s. al-Mujadalah : 11)",

Dalam hal pembelajaran dan pemberian motivasi, politik merupakan rumpun ilmu pengetahuan yang mana mahasiswaa setidaknya mampu memahami dan menganalisis, mensisntesa eksistensi dan ilmu-ilmu sosial dan politik dalam tataran kehidupan bermasyarakat serta dalam dunia pergerakan dalam dakwah kampus sehingga implikasi pembelajaran Kursus itu adalah masyarakat kampus. dalam memahami system pendidikan 
politik Islam, pemahaman mahasiswa terhadap suatu referensi system pendidikan Islam harus di bimbing dan diarahkan agar bisa terarah dan terkontrol dalam memahami dan mempraktekan ilmu politik yang didapatkan didalam Kursus tersebut. Gerakan yang muncul dan sifat mahasiswa terhadap nilai-nilai politik Islam itu membutuhkan wadah atau tempat untuk melakukan pendekatan emosional dan membutuhkan mobilisasi-mobilisasi untuk bisa di arahkan pada politik yang baik dan Islami.

\section{Training kepemimpinan}

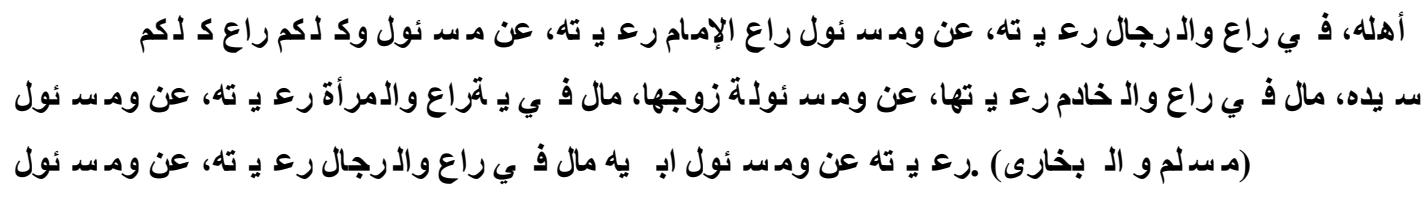

"Hadis Ibnu Umar r.a. Diriwayatkan daripada Nabi s.a.w berkata: baginda telah bersabda: kaтu semua adalah pemimpin dan kamu semua akan bertanggungjawab terhadap apa yang kamu pimpin. Seorang pemerintah adalah pemimpin manusia dan dia akanbertanggungjawab terhadap rakyatnya. Seorang suami adalah pemimpin bagi ahli keluarganya dan dia akan bertanggungjawab terhadap mereka. Manakala seorang isteri adalah pemimpin rumahtangga, suami dan anak-anaknya, dia akan bertanggungjawab terhadap mereka. Seorang hamba adalah penjaga harta tuannya dan dia akan bertanggungjawab terhadap jagaannya. Ingatlah, kaтu semua adalah pemimpin dan akan bertanggungjawab terhadap apa yang kamu pimpin"

Proses pengkaderan yang terjadi di LDK UKKI UHO dilaksanakan melalui Tadrib (Training) yang dilakukan secara sadar, terencana, sistematis, dan berkesinambungan, serta memiliki pedoman dan aturan yang baku secara rasional dalam rangka mencapai tujuan LDK UKKI UHO agar bisa mencapai standar Kepemimpinan (Kekhalifahan) yang baik dan Islami. Untuk mendidik seorang calon Pemimpin atau khalifah tentunya harus mempunyai materi pelatihan Kepemimpinan (Kekhalifahan) yang baik. Materi pelatihan ini diberikan agar para calon Pemimpin atau khalifah ini mengerti benar bagaimana harus memimpin dan bagaimana harus bersikap sebagai seorang Pemimpin

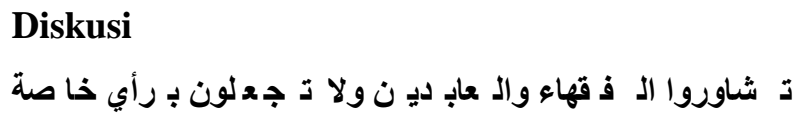

Diskusi

ت شاوروا الل ف قهاءو وال عاب دي ن ولا ت جعلون بـ رأي خاصة 
"Hendaklah kamu bermesyuarat dengan ahli fiqh (orang-orang yang mempunyai pengertian tentang agama) dan orang-orang ahli ibadat, dan janganlah kamu putuskan dengan fikiran sendiri( Riwayat Ath-Thabarani)"

Penanaman pemahamanan politik di dalam ruang lingkup lembaga dakwah kampus UKM UKKI UHO telah tersusun secara merata, bahkan ada program-program yang berhubungan langsung dengan sistem nilai politik Islami. sistem penanaman materi munaqhasa politik lembaga dakwah kampus UKM UKKI UHO menjadi agenda-agenda penting termasuk dalam menanggapi isu-isu yang berkembang di Negara Indonesia maupun di tataran akademik kampus universitas Halu Oleo. Materi-materi munaqhasa yang berkaitan

\section{Keikut Sertaan Dalam Forus Pertemuan}

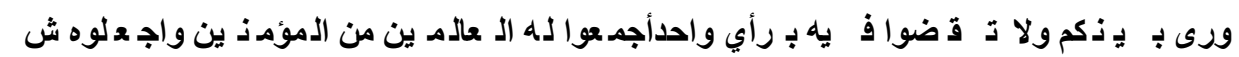

"Hendaklah kamu adakan kerapatan dengan orang-orang yang beriman, dan adakan lah permusyawaratan di antara kamu dan janganlah kamu memutuskan dengan fikiran sendiri (Riwayat Imam Ibn Abdil-Barr) '”

Partisipasi politik Islam LDK UKM UKKI UHO penting sekali dalam rangka dukungannya terhadap program atau kebijakan yang hendak ditetapkan oleh khalifahnya. pertemuan dalam forum-forum LDK UKM UKKI dalam rangkapergantian Ketua/kepengurusan LDK UKM UKKI dan memutuskan calon-calon anggota LDK UKM UKKI yang akan di calonkan di pesta demokrasi kampus sebagai perwakilan dari LDK UKM UKKI UHO.

\section{KESIMPULAN}

Dari hasil penenelitian yang dilakukan oleh penulis terkait dengan pendidikan politik Islam melalui organisasi kemahasiswaan pada pengkaderan lembaga dakwah kampus penulis menyimpulkan bahwa:Proses pengkaderan yang dilakukan oleh lembaga dakwah kampus unit kegiatan kerohanian Islam Universitas Halu Oleo sangat sistematis, dalam kegiatan pengkaderan yang dilaksanakan mempunyai tahapan-tahapan sesuai dengan pedoman pengkaderan LDK UKKI dimulai dari Tadrib Mustawaan Wahid (Training TingkatI / TR I), Tadrib Mustawaan altthani (Training TingkatII / TR II) yang mengikuti semua agendaagenda kegiatan LDK UKKI sebagai sarana pendidikan politik Islam di dalam kampus. Namun sebelum sampai pada tahapan TR-I dan TR-II kader terlebih dahulu harus melalui 
pembinaan selama kurang lebih Enam Bulan di MPM-MPM masing-masing fakultas melalui kegiatan Tarbiyah.Pendidikan politik Islam yang diberikan Kepada mahasiswa pada pengkaderan di orgaisasi Lembaga Dakwah Kampus Unit Kegiatan Kerohanian Islam Universitas Halu Oleo adalah melalui kegiatan Kursus, Training kepemimpinan, Diskusi serta Keikut Sertaan Dalam Forus Pertemuan hal ini dapat mempengaruhi dan meningkatkkan pengetahuan politik Islam pada mahasiswa. Hal ini dapat dilihat ketika pergantian kepengurusan di LDK UKKI serta pemilihan-pemilihan anggota LDK UKKI yang akan di calonkan di pesta demokrasi kampus selalu menggunakan cara Islami dalam hal ini sistem syuro atau musyawarah.

\section{DAFTAR PUSTAKA}

Abdul wahab as-Siyasahasy-Syari'ahwa mafhum as-Siyasahal- Hadits,

Bungin, Burhan. 2011, Metode Penelitian Kualitatif, Jakarta: Kencana Perdana Media

Eprints.uny.ac.id. tinjauan tentang politik islam/2007401244002.pdf diakses pada tanggal 22 Mei 2019.

Hamid,TijaniAbdulQadir.PemikiranPolitikAl-Qur"an.Cet.I;Jakarta:GemaInsaniPress,2001.

IbnaqilAs-Siyasahasy-Syari,, ahfilslahal-Ra,,iwaal-Ra,,iyyah.Daral- Kutubal-

„Arabiyat,Bairut, 1966.

Kairo: al-Ma'had al-Alamili al-Fikr al- Islami,1997.

Moloeng, L. J. 2002, metode penelitian kualitatif. Bandung: PT. Remaja Rosda Karya

Sahih Al-Bukhari translated by M. Muhsin Khan 2018

Sugiyono, Amin. 2010. Ijtihad Membangun Basis Geraka.Bekasi: Muda Cende kia.

Sunan Abu-Dawud translated by Prof. Ahmad Hasan 2018

Surbakti, Ramlan. 1999. Memahami Ilmu Politik. Jakarta: Gramedia 